pp. $81-90$, April 2020

\title{
Effect of Tackifier Addition on Cushion Compound Formulation for Tire Retreading Application
}

\author{
Lies Agustine Wisojodharmo ${ }^{1}$, Dewi Kusuma Arti ${ }^{1}$, Retna Deca Pravitasari ${ }^{1}$, Ade Sholeh Hidayat ${ }^{1}$, \\ Aisyah I. Nisa ${ }^{2}$, and Muhammad N. Ariesta ${ }^{2}$
}

1) Center of Technology for Material, Agency for Assessment and Application of Technology, Bld 224

Puspiptek South Tangerang 15314, Indonesia

2) Chemistry Department, Faculty of Mathematic and Sciences, Universitas Sebelas Maret, Ir. Sutami No.36 A Surakarta, 57126, Indonesia

*Corresponding author : $\underline{\text { lies.agustine@bppt.go.id }}$

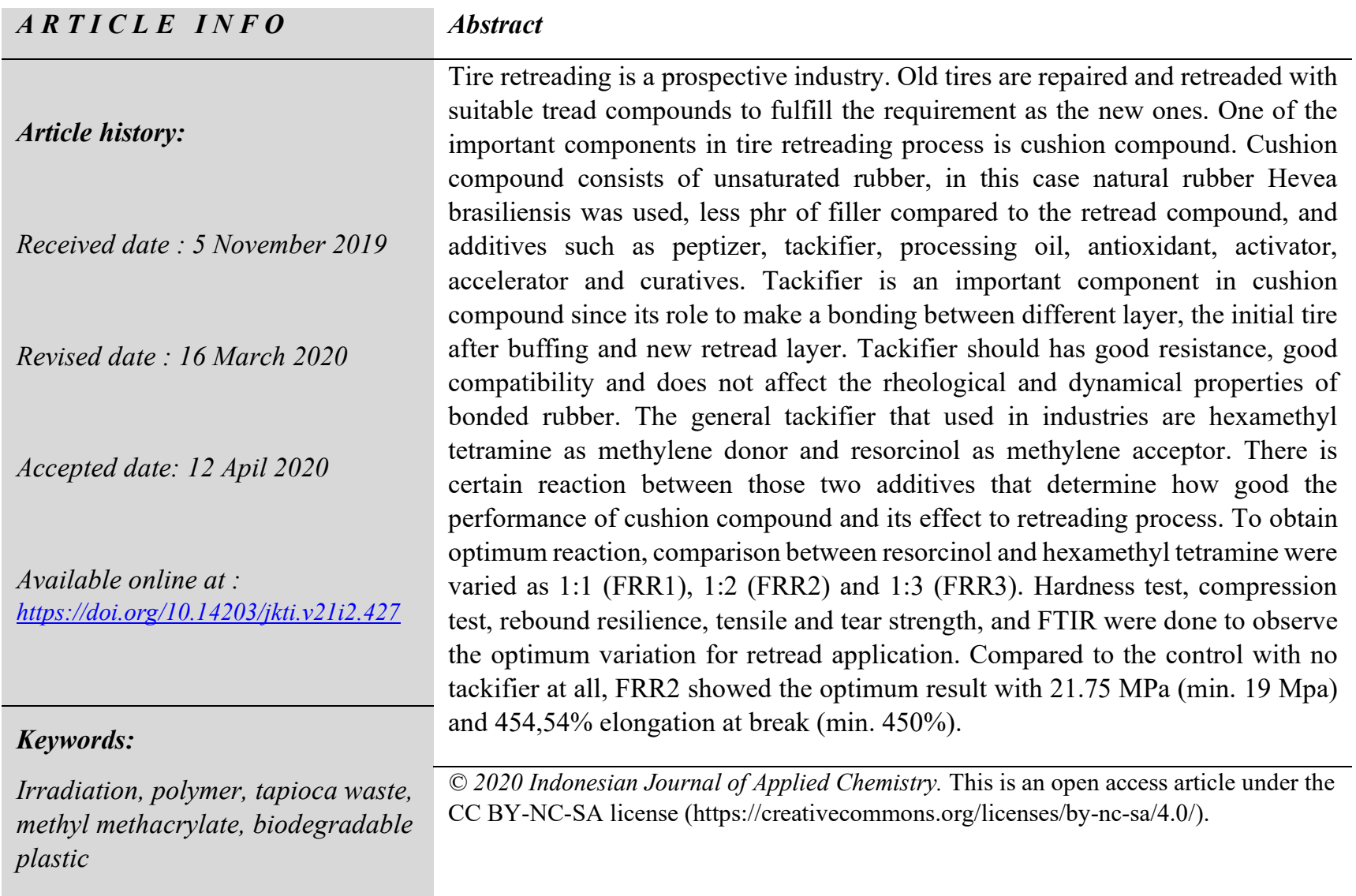

\section{INTRODUCTION}

The tire is one of the biggest application of natural rubber. Tire retreading is recondition of the smooth tire surface coated with new rubber to extend the life of tire use. With tire retreading production, will reduce dependence on aircraft tire imports from abroad and provide performance and quality that is almost close to a new tire.

"Effect of Tackifier on Cushion Compound Formulation...": Lies A. Wisojodharmo, et.al.| 81 
The tire retread is the formation of crosslinking of elastomer molecules in rubber compounds. The surface of tire retread that has been buffing is attached to a new tread layer using cushion gum. Cushion gum consist of unsaturated diene natural rubber and additives such as tackifier, homogenizer, processing oil, plasticizer, filler, activator, accelerator, antioxidant and curative.

Tackifier is one important additive that consists of hexamethyl tetramine as methylene donor and resorcinol as methylene acceptor which added to rubber compound to bind materials during the processing to curing process [1]. Tackifier has rubber stripping resistance properties, good rubber compatibility and does not affect the rheological and dynamic properties of the glued rubber. Tackifier works on the surface of the compounds through the various types of chemical interaction that bind two pieces of rubber put together. In general, chemical interaction that occurs in the tackifier are chemical bonds during vulcanization process and hydrogen bonds that form by the intermolecul phenol tackifier and van der wall bonding [2]. The goals of this study is evaluating the effect of tackifier composition addition on cushion compound formulation for tire retreading application.

Based on the source, the tackifier can be classified into two types namely natural and synthetic. Natural tackifier comes from rosin and terpen, and synthetic tackifier comes from petroleum, coal, and phenols. Phenolic resin is a type of tackifier that is commonly used in tire manufacturing [3]. Phenolic resins are divided into two types namely resol and novolac resins based on the functional group. Novolac has an average molecular weight of $500-3000 \mathrm{~g} / \mathrm{mol}$ with the connection structure methylene bridge $\left(-\mathrm{CH}_{2}-\right)$. This resin forms a crosslink with methylene donor as curing agent in the form of Hexamethylnetetramine HMT) or Hexamethoxymethylmelamine (HMMM). Resol has an average molecular weight of 500-1500 $\mathrm{g} / \mathrm{mol}$ which this structure associated with methylol end groups (- $\left.\mathrm{CH}_{2} \mathrm{OH}-\right)$. Resol will form a crosslink through heating. The mechanism of phenolic resins showed in figure 1. The hydrogen attached to the benzene ring in para and ortho position of the hydroxyl group can react with methylene donor and form a crosslink [4].

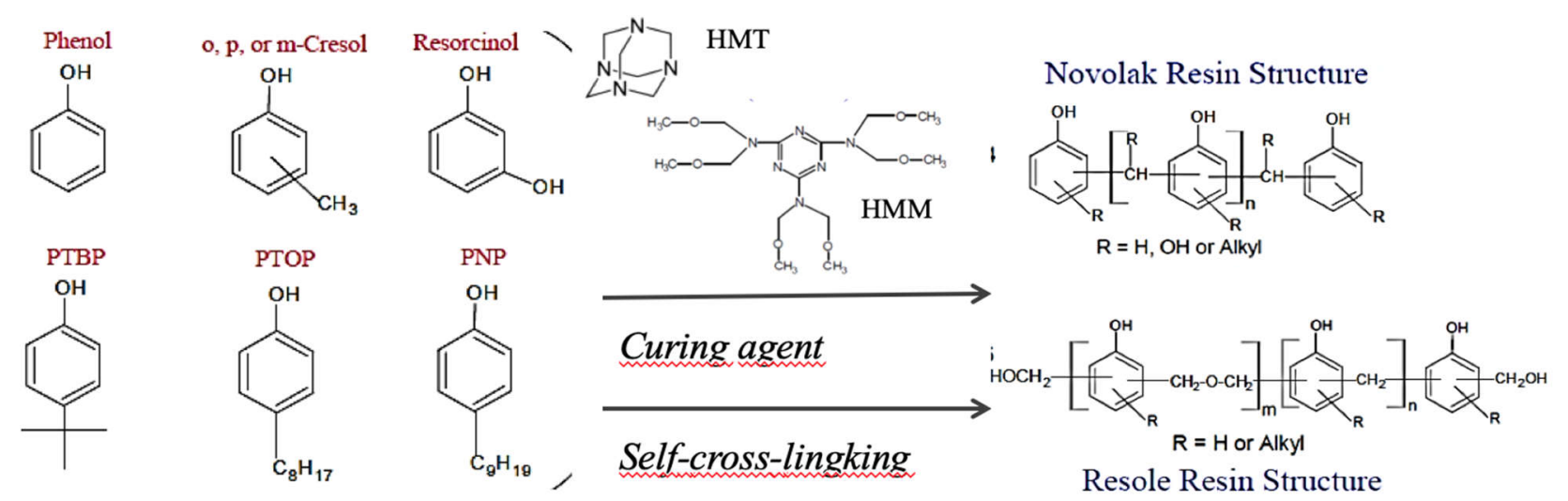

Fig. 1. Phenolic resin reaction [4] 
The tackifier consists of resorcinol as methylene acceptor and hexamethyl tetramine as methylene donor. Resorcinol works as an adhesion between rubber and reinforcing materials formed during the curing process. The preparation of resorcinol can be through the reaction of benzene sulfonation with the addition of $\mathrm{SO}_{3}$ and $\mathrm{NaOH}$ that showed in figure $2[5]$.

Some types of chemical that contain Methylene donor in the tackifier can be using a curing agent such as Hexamethylenetetramine (HEXA) or Hexamethoxymethylmelamine (HMMM). HEXA-80 is a methylene donor which has a main composition of $80 \%$ Hexamethylenetetramine and $20 \%$ elastomer. The addition of HEXA- 80 speeds up the curing process and form a high degree of crosslink. Hexamethylenetetramine is made through the condensation reaction between formaldehyde with ammonia in an acidic atmosphere. The reaction showed in figure 3 [6].

The reaction between Resorcinol and Hexamethylenetetramine as a tackifier showed in figure 4 [4]. Tackifier of novolac will form crosslink the reaction of Resorcinol as a methylene acceptor and HEXA as a methylene donor. HEXA will donate the methylene group to Resorcinol. At the resorcinol structure, substituted benzene on 1,3 hydroxyl group will be substituted by methylene at the ortho and para position to form a crosslink. These crosslink will react with rubber to produce chroman ring and methylene bridge [4].

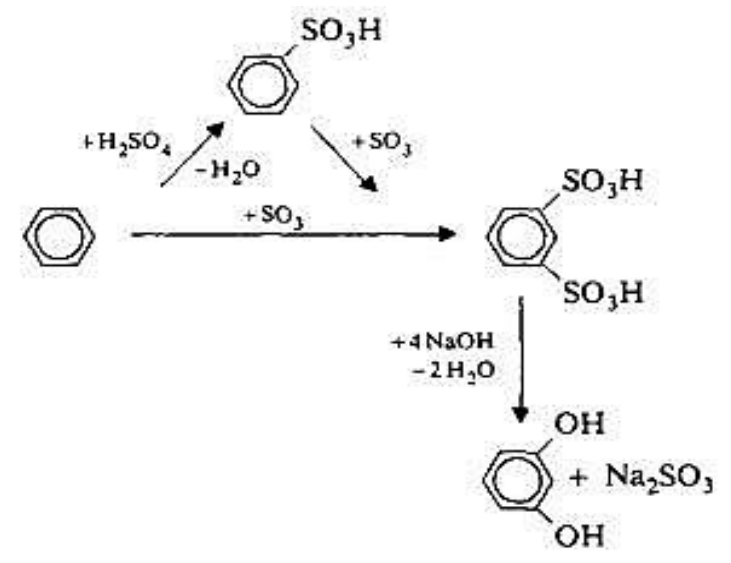

Fig. 2. Resorcinol forming [5]

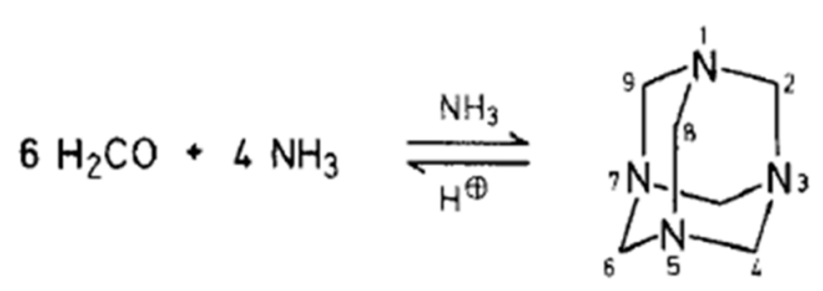

Fig. 3. Hexamethylenetetramine forming [5]

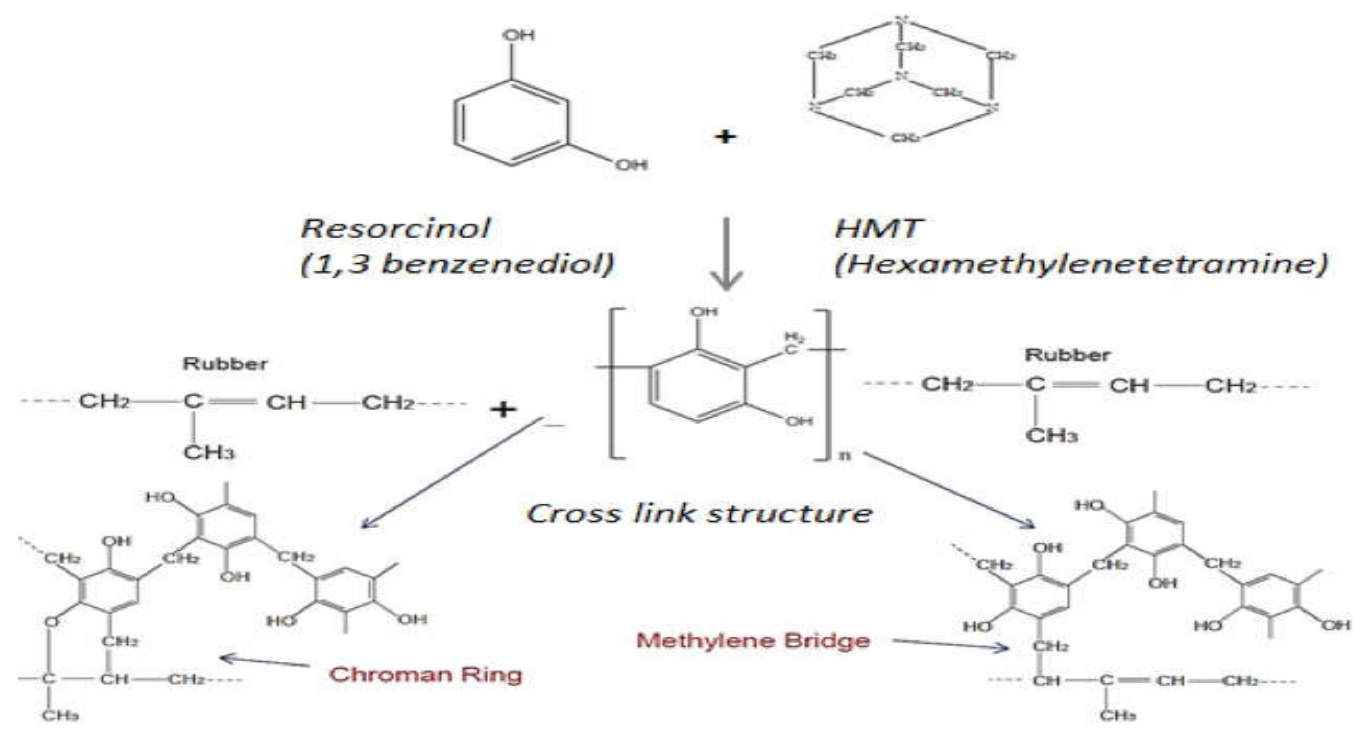

Fig. 4. Reaction of resorcinol and Hexamethylenetetramine [4]

"Effect of Tackifier on Cushion Compound Formulation...": Lies A. Wisojodharmo, et.al. | 83 
pp. $81-90$, April 2020

\section{EXPERIMENTAL}

\subsection{Materials}

The ribbed smoked sheet (RSS-1), aktiplast 8, zinc oxide $(\mathrm{ZnO})$, stearic acid, carbon black $\mathrm{N}$ 660, 2,2,4-trimethyl-1,2-dihydroquinoline (TMQ), n-(1,3-dimethylbuthyl)-n'-phenyl-pphenylenediamine (6PPD), sulfur, n-cyclohexyl2benzothiazolesulfenamide (CBS), paraffinic oil, and SIR were purchased from PT Graha Jaya Pratama Kinerja. Resorcinol and hexamethylene tetraamine (Renogran HEXA 80) as tackifier materials were purchased from PT Multi Citra.

\subsection{Methods}

\subsubsection{Rubber Compounds}

Table 1. Formulation design in phr

\begin{tabular}{ccccc}
\hline Components & \multicolumn{4}{c}{ Formula (phr) } \\
\cline { 2 - 5 } & FRR1 & FRR2 & FRR3 & FRR4 \\
\hline NR & 100 & 100 & 100 & 100 \\
\hline ZnO & 50 & 50 & 50 & 50 \\
\hline Stearic Acid & 2.5 & 2.5 & 2.5 & 2.5 \\
\hline TMQ & 1.25 & 1.25 & 1.25 & 1.25 \\
\hline Carbon & 45 & 45 & 45 & 45 \\
Black N660 & & & & \\
\hline Resorcinol & 1.6 & 2.4 & 1.2 & 0 \\
\hline Renogran & 3.2 & 2.4 & 3.6 & 0 \\
Hexa-80 & & & & \\
\hline Sulfur & 1.5 & 1.5 & 1.5 & 1.5 \\
\hline 6PPD & 1.25 & 1.25 & 1.25 & 1.25 \\
\hline CBS & 0.7 & 0.7 & 0.7 & 0.7 \\
\hline Aktiplast & 0.4 & 0.4 & 0.4 & 0.4 \\
\hline Paraffinic & 7.5 & 7.5 & 7.5 & 7.5 \\
Oil & & & & \\
\hline
\end{tabular}

Four rubber compounds formula with different composition of tackifier were prepared. The ratio tackifier of resorcinol/Hexa 8 were 1.6/3.2, 2.4/2.4, 1.2/3.6, and $0 / 0(1: 2 ; 1: 1 ; 1: 3$; and $0: 0)$. The formulations are given in table 1 . Rubber compounds were blended in kneader type mixer at $100{ }^{\circ} \mathrm{C} 32 \mathrm{rpm}$ for 5 minutes. The compounds made sheet on the open mill at $70{ }^{\circ} \mathrm{C}$ and kept at room temperature for 24 hours. Rubber compounds were blended again in kneader type mixer at $70{ }^{\circ} \mathrm{C} 32 \mathrm{rpm}$ for 2 minutes. CBS and sulfur were added into the compounds for 2 minutes. The compounds made sheet again on the open mill at $70^{\circ} \mathrm{C}$.

\subsubsection{Characterization}

\subsubsection{Fourier transform infra red (FTIR)}

FTIR was measured by iS50 FT-IR Smart iTR with wave number $4000-500 \mathrm{~cm}^{-1}$ by using ATR method without preparation to the compounding sample.

\subsubsection{Thermo gravimetric analyzer (TGA)}

TGA was measured by TG DTA DSC labsysEvo as followed by ASTM D6370. Weight of samples is around 10-12 mg.

\subsubsection{Hardness test}

The hardness was measured by Shore A Mutituyo Durometer hardness tester as followed by ASTM D2240. Each samples was taken five measurement with different positions with a distance of at least $6 \mathrm{~mm}$.

\subsubsection{Rebound resilience test}

Rebound Resilience was measured by Gibitre Instruments Rebound Check Resilience Tester. Before testing, encoder was setting on \pm 0.05 and $\pm 90^{\circ} \mathrm{C}$.

\subsubsection{Compression set test}

Compression set test was measured by compression device as followed by ASTM D395 at $70{ }^{\circ} \mathrm{C}$ for 22 hours and kept at room temperature for 1 hour.

\subsubsection{Density}

The density was measured by analytic balance GR-200 as followed by ASTM D297-15.

\subsubsection{Tensile and tear strength}


pp. $81-90$, April 2020

Tensile and tear strength were measured by universal testing machine (UTM) Geotech Al7000-S as followed by ASTM D412.

\section{RESULT AND DISCUSSION}

\subsection{Fourier Transform Infra Red (FTIR)}

In the resorcinol structure in Fig 2, OH groups substitute benzene in position 1 and 3 causing C$\mathrm{H}$ in meta position does not appear. While $\mathrm{C}-\mathrm{H}$ in ortho and para position unsubstituted so the spectra appear in the IR spectrum. The reaction of HEXA and resorcinol forms a crosslink can be seen in IR FRR2 on figure 5 that the C-H group at ortho and para position is missing and forming a new chemical bond that is methylene bridge the result react of curing effect.

The IR spectrum of tire retread (FRR1 FRR4) does not show an initial bond of HEXA. Based on the result oi figure 5, in the area of $1500-1400 \mathrm{~cm}^{-1}$ was found that increasing the number of HEXA on the ratio will reduce the peak intensity of the methylene bridge formed. The area of the spectra shows a phenolic ringsubstituted on para and ortho position. The instensity decrease due to the reduction of mono substituted phenolic ring and the occurrence of crosslinking [7].

In the FRR4, the color changes from black to gray spot cause by the effect of blooming that occur in the rubber compound. Blooming that occur in FRR4 is a substance in the rubber matrix reacting with the environment element. This blooming is caused by excessive use of 6 PPD and Zinc Stearate. However, blooming did not form on FRR1, FRR2, and FRR3 which uses a tackifier. Therefore, tackifier can also bind the excess substance in the rubber compound. In figure 6 shows the IR spectrum comparison FRR4 before and after blooming. The blooming because of the water in the atmosphere which seen the intermolecular hydrogen $\mathrm{O}-\mathrm{H}$ at 3278 $\mathrm{cm}^{-1}$ area. 


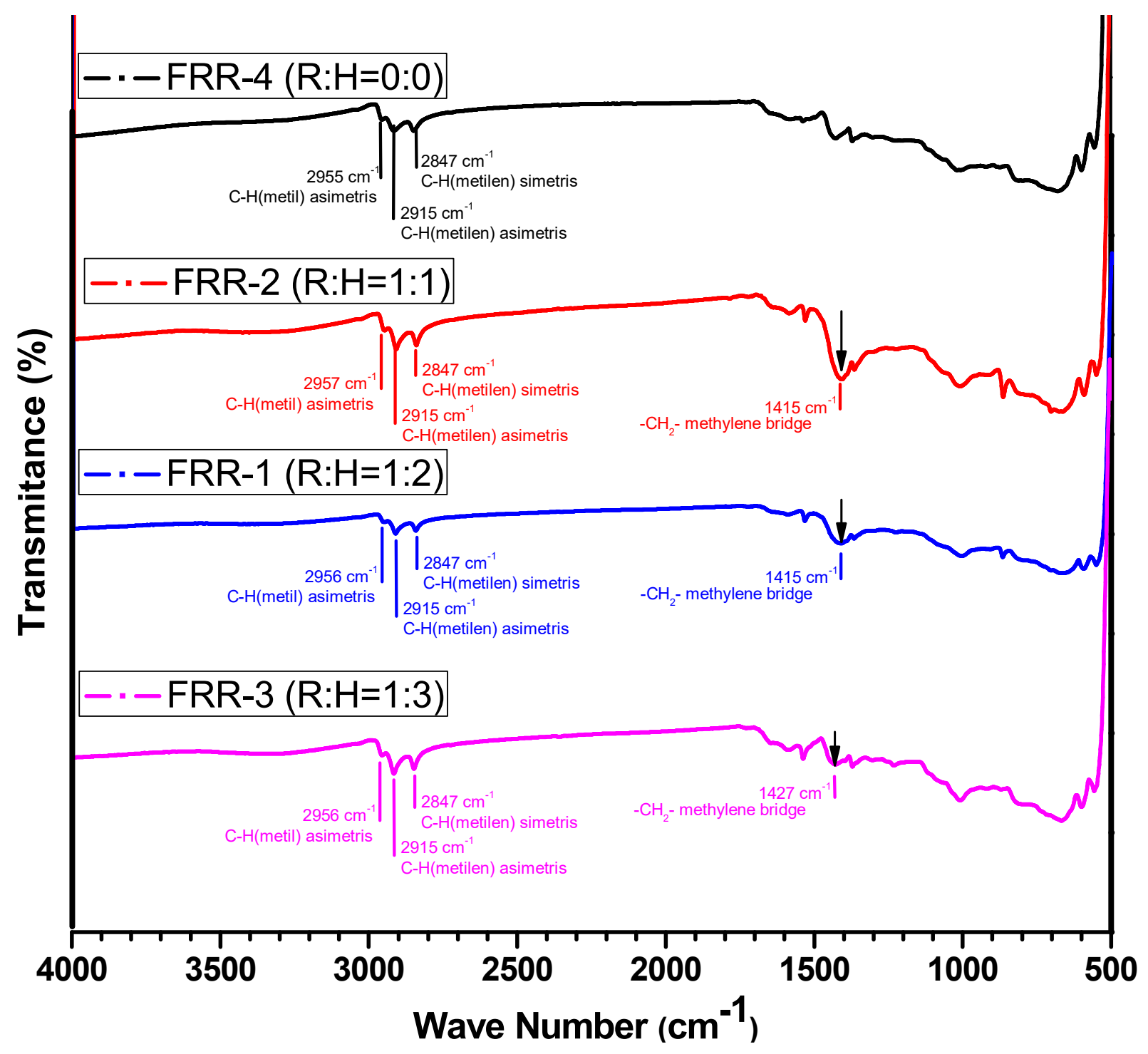

Fig. 5. IR Spectrum of FRR1, FRR2, FRR3, and FRR4. 


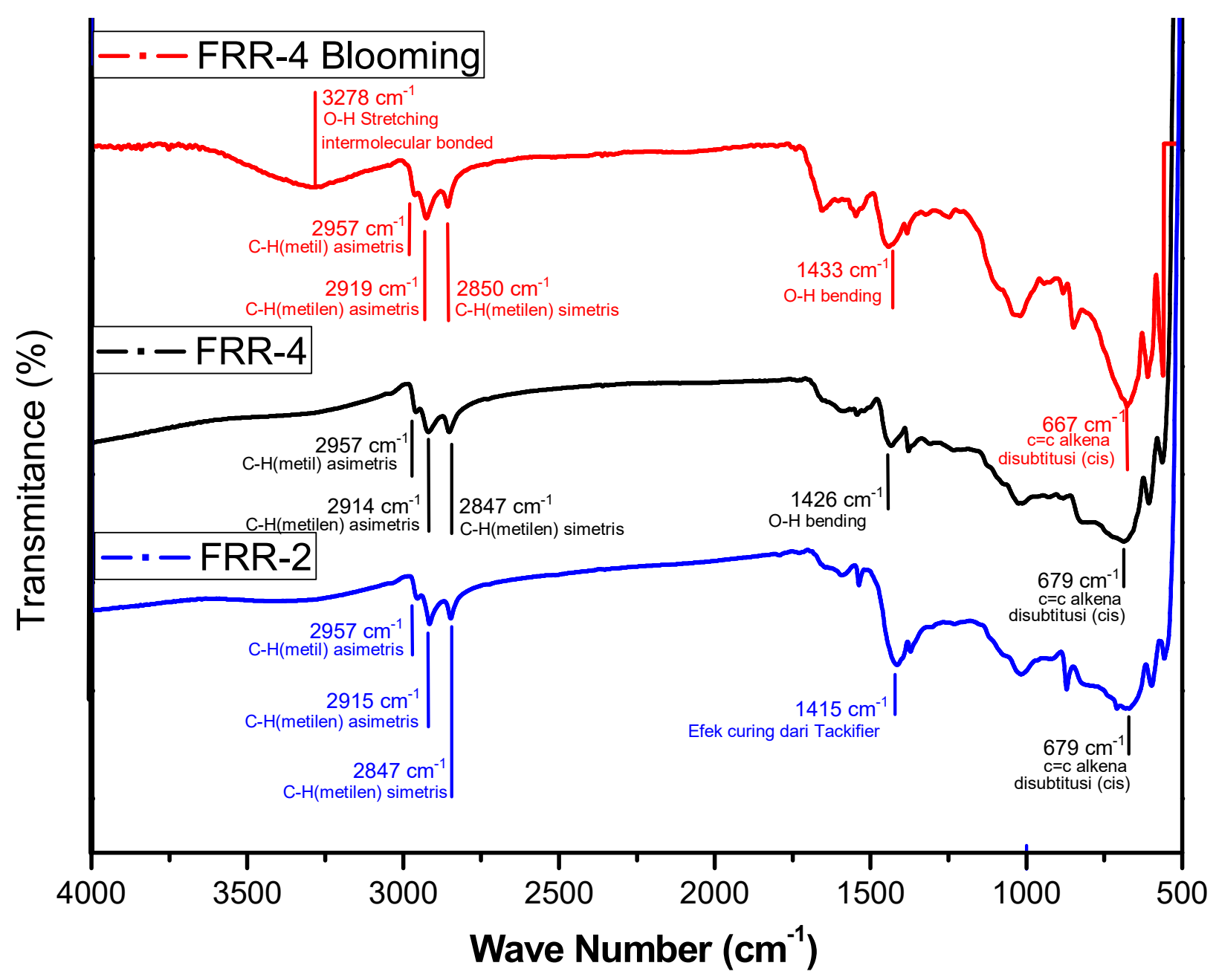

Fig. 6. Blooming effect at FRR4.

\subsection{Thermo Gravimetric Analyzer (TGA)}

Figure 7 was obtained based on ASTM D637, which there was cooling step before changing the atmosphere of testing from inert gas to Oxygen. As shown in figure 7, each cushion gum formula obtained the same trend graph that has 2 decompositions. The first is the main matrix of natural rubber (RSS1) and the second is filler carbon black. According to the literature, natural rubber began to decompose at $\pm 240^{\circ} \mathrm{C}$ and carbon black at $625^{\circ} \mathrm{C}[8,9]$. The initial formulation of RSS1 in FRR4 was $60,361 \%$ and the change in mass increased to $63,349 \%$ because curing effect from sulfur.
While, the effect of the ratio of tackifier (Resorcinol/Hexa-80) are seen in thermogram of FRR1, FRR2, and FRR3. The results show that added tackifier will decrease decompose temperature of rubber but increasing the crosslinker density of rubber with increasing the mass of HEXA- 80 on the tackifier ratio. The increasing amount of HEXA-80 on the ratio tackifier also increases rubber temperature decompose but has no effect to carbon black. The optimal effect of the addition of tackifier can be seen on FRR2 with ratio resorcinol/HEXA-80 $1: 2$, it has the highest mass of matrix and filler changes of $70,096 \%$ and $29,746 \%$, respectively. 
pp. $81-90$, April 2020

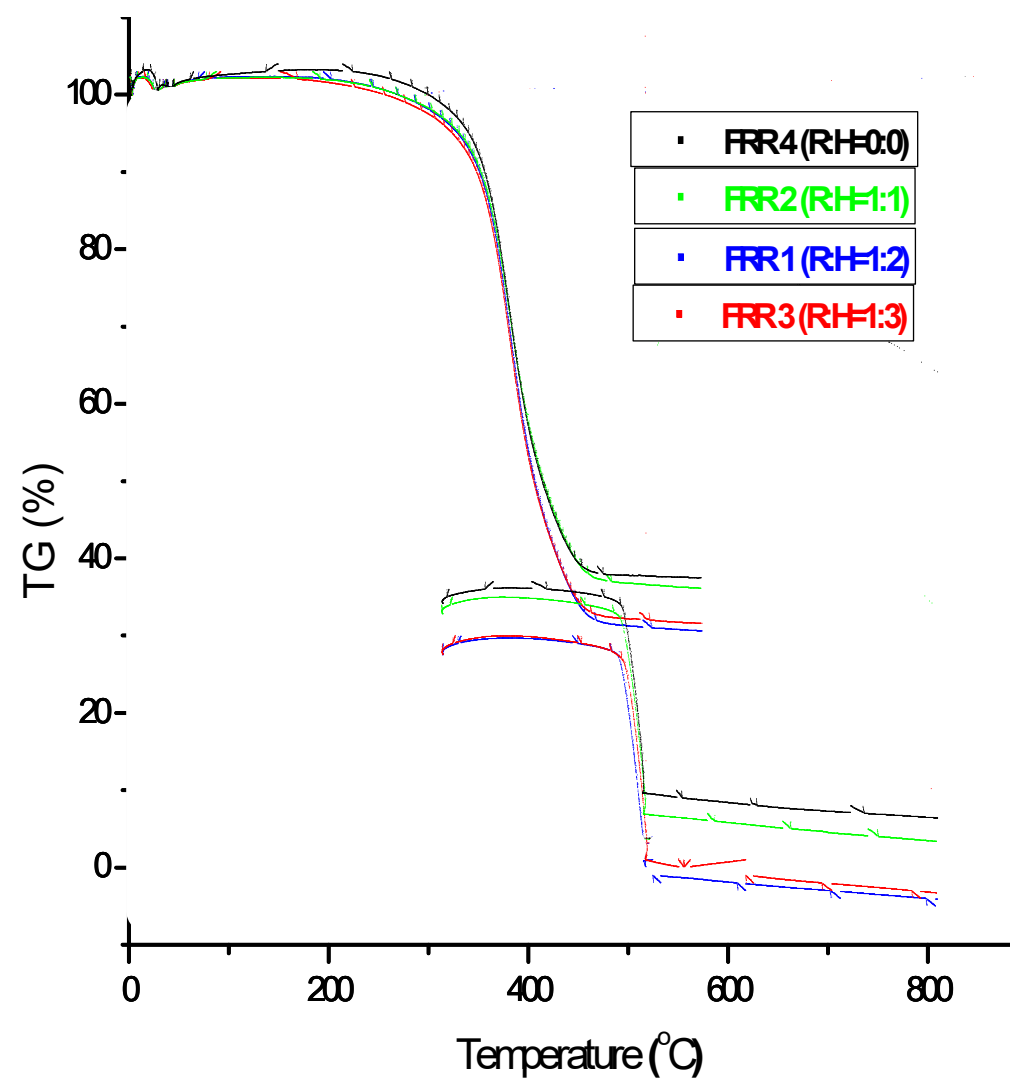

Fig. 7. Thermogram of FRR1, FRR2, FRR3, and FRR4.

\subsection{Hardness and Rebound Resilience Test}

The addition of tackifier will increasing hardness and decreasing rebound value [10]. The tackifier will bind the rubbers to form strong bonds. In figure 8 shows the hardness increase at the ratio 1:1 but decrease with adding HEXA on the ratio. The rebound value is correlative with the hardness, when it increases then the rebound will be decrease.

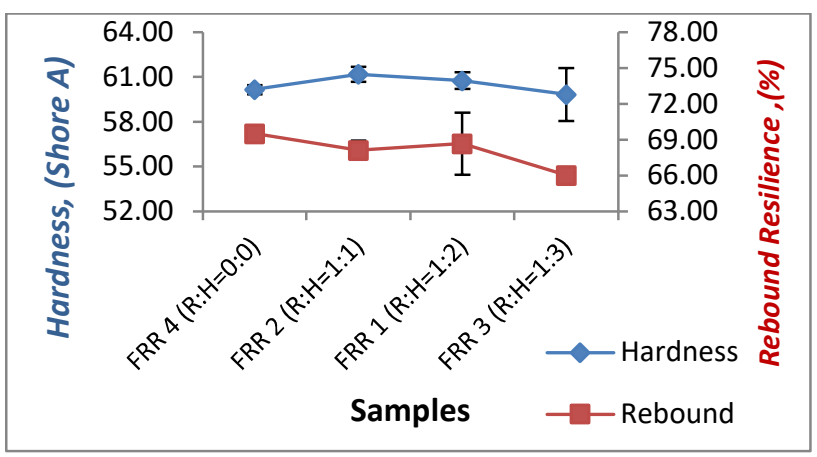

Fig. 8. Hardness and Rebound Resilience of FRR1, FRR2, FRR3, and FRR4

\subsection{Compression Set and Density}

As shown in figure 9, the compression of FRR2 decrease significantly compared to FRR4 by $70,37 \%$. The Lower compression set is good for dynamic tire performance so that the material can return to its initial size after use. The density increase at FRR2 compared to FRR4. However, the trend of density value decreased with the addition of HEXA to the tackifier.

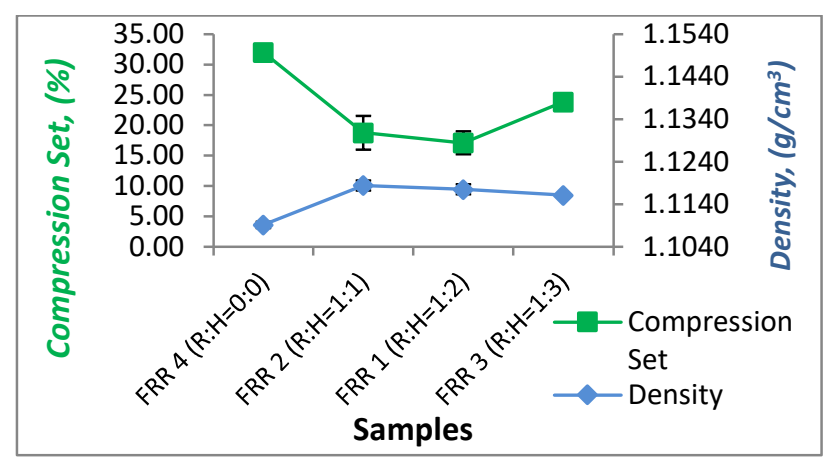

Fig. 9. Compression Set and density of FRR1, FRR2, FRR3, and FRR4

88 | "Effect of Tackifier on Cushion Compound Formulation...": Lies A. Wisojodharmo, et.al. 
pp. $81-90$, April 2020

\subsection{Tensile and Tear Strength}

The addition of tackifier increased the tensile and tear strength have shown in figure 10 and 11. The optimum ratio of these properties is $1: 1$. The tensile and tear strength increasing $6,15 \%$ and $8,24 \%$ respectively, from FRR-4 to FRR-2. The increasing of HEXA 8, will decrease the properties. These properties correlative with IR FRR2 that have the biggest curing effect make the rubber compound stronger.

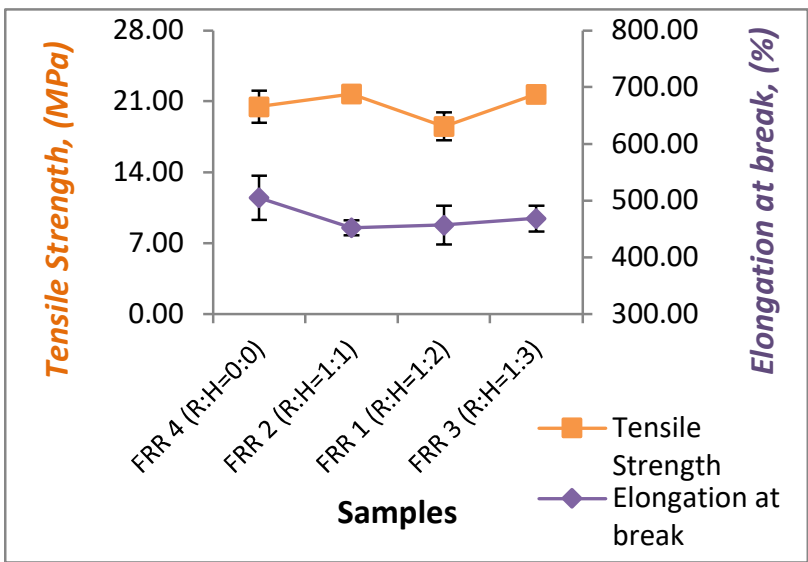

Fig. 10. Tensile strength of FRR1, FRR2, FRR3, and FRR4

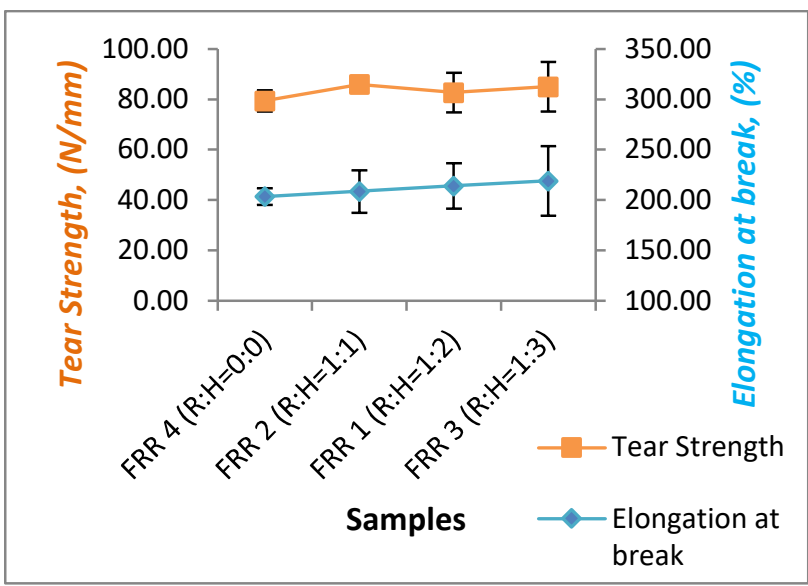

Fig. 11. Tear strength of FRR1, FRR2, FRR3, and FRR4.

\section{CONCLUSION}

The optimum of tackifier ratio of rubber compound is $1: 1$. That ratio seen the properties of cushion gum will increasing the hardness, tensile and tear strength, and density. Increasing HEXA-80 on the ratio will be decrease the properties. The optimum ratio also shown on IR FRR 2 that have new chemical bond. Thus FRR 2 is potential to be used as cushion gum for retreading tire application.

\section{ACKNOWLEDGMENT}

The authors would like to acknowledge The Centre for Materials Technology (BPPT), Indonesia, for supporting the financial to conduct this research.

\section{REFERENCES}

[1] Anonim-7. "Phenolic Resin as Tackifiers in Rubber Compounds". Ram Charan Company, Chennai. 2014.

[2] Anonim-8. "Phenolic Resins for The Rubber Industry-An Overview". Ram Charan Company, Chennai. 2012.

[3] Megson, N.J.L. "Phenolic Resin Chemistry". Butterworths Scientific Publications, California. 1995.

[4] Durairaj, R.B. "Resorcinol: Chemistry, Technology and Applications". Springer Berlin Heidelberg, New York. 2005.

[5] Dressler, H. "The Properties and Chemistry of Resorcinol". In Resorcinol. Springer, Boston, MA. 1994.

[6] Eller, K., Henkes, E., Rossbacher and R. Höke, H. "Amines, Aliphatic7 Ullmann's Encyclopedia of Industrial Chemistry". Wiley-VCH Verlag GmbH. 2000.

[7] Aranguren, M.I., Borrajo, J. and Williams, R.J.J. "Some Aspects of Curing Novolac with Hexamethylenetetramine". Journal of Polymer Science Part A: Polymer Chemistry, vol. 20, no.2, pp.311-318. 1982. 
pp. $81-90$, April 2020

[8] Zeid, M.M.A. "Radiation Effect on Properties of Carbon Black Filled NBR/EPDM Rubber Blends". European Polymer Journal, vol.43, no.10, pp. 44154422. 2007.

[9] Wisojodharmo, L. A., Fidyaningsih, R., Saputra, D.A. dan Fitriani, D.A. 2016. Pengaruh Variasi Peptizers Terhadap Viskositas dan Sifat Fisik Kompon Karet. Jurnal Sains Materi Indonesia. vol.17, no.3, pp. 110-114.

[10] N. Rattanasom, S. Prasertsri and T. Ruangritnumchai. 2009. Comparison of the mechanical properties at similar hardness level of natural rubber filled with various reinforcing-fillers. Polymer Testing. vol.28, no.1, pp. 8-12. 